\title{
Study on the Construction of Tourism Marketing System of Hani Terrace in Yuanyang
}

\author{
Mingqiang $\mathrm{Lu}^{1}$ \\ ${ }^{1}$ Qinhuangdao Branch of Northeast Petroleum University, Qinhuangdao 066004, China \\ Correspondence: Mingqiang Lu, Qinhuangdao Branch of Northeast Petroleum University 112box, Qinhuangdao \\ city 066004, Hebei Province, China. E-mail: 324wxm@sian.com
}

Received: January 28, 2015 Accepted: March 4, 2015 Online Published: March 28, 2015

doi:10.5539/ijms.v7n2p99 URL: http://dx.doi.org/10.5539/ijms.v7n2p99

\begin{abstract}
Terraced landscape of Yuanyang Hani is extremely rare at home and abroad. Since the 1980s, there have been great concerns about Yuanyang Hani Terrace. Although tourists and tourism revenue have increased quantitatively, there are only a few researches of tourism Market and Marketing Strategies about Yuanyang Hani Terrace. Based on the investigation of the characteristics of Hani terrace tourism market, the study builds Yuanyang Hani terrace tourism marketing system, which includes the overall marketing target, marketing organization, marketing strategy and marketing control, etc. Moreover, the system is of great importance for promoting the overall and healthy development of local tourism.
\end{abstract}

Keywords: tourism marketing strategy, Hani Terrace, Yuanyang

\section{Background and Significance}

Yuanyang County is located in the southern part of Yunnan Province, southern part of Ailao Chains, southern part of Honghe Region and southern bank of Honghe River. It is situated between eastern longitude $102^{\circ} 27^{\prime}-103^{\circ} 13^{\prime}$ and northern latitude $22^{\circ} 49^{\prime}-23^{\circ} 19^{\prime}$. The terrace in Yuanyang extends across Honghe River, Yuanyang, Lvchun and Jinping as well as other counties on the southern bank of Honghe River with grand and magnificent scale. Only within Yuanyang County, the terrace covers 170,000 mu land, which is the core of Hani terrace in Honghe. In Yuanyang County, there are towering and steep mountains. All terraces are built on the mountains with the slope ranging from $15^{\circ}$ to $75^{\circ}$. The highest single terrace reaches 3,000 stairs, which can be rarely seen in domestic and foreign terraces. Hani terrace is a typical example of the harmony between people and nature. In 2013, Hani terrace in Yuanyang was rated into "China World Cultural and Natural Heritage List" formally by UNESCO. Since 2001, the number of tourists in Yuanyang terrace has increased rapidly. Although the number of tourists and tourism income increase greatly, there are few researches on Hani terrace. At present, the literatures associated with Yuanyang terrace travel elaborate on rice-farming culture (Zhu, 2009), photography, resource protection and development (Luo, 2003; Rao, 2009; Hu, 2008), ecological tourism (Huang, 2004; Lu, 2006), community tourism (Liu, 2008), ethnical culture (Jiao, 2002; Zhang, 2003) and so on. No specific researches on Hani terrace tourism market or marketing in Yuayang are provided. Because the region lacks tourism market investigation for a long time, leaders and managers do not master the direction of tourists' authentic demands and tourism development well. Till now, no systematic Toursim Marketing system has been formed. Under such a background, it is of great importance for promoting the overall and healthy development of local tourism to construct Toursim Marketing system of Hani terrace in Yuanyang.

\section{Methodology}

\subsection{Literature Analysis Methodology}

The study widely collects domestic and foreign experts' researches on tourism marketing, community development, community tourism, tourists' perception and behaviors, tourism's effects and so on, summarize and conclude the literatures, and make a summary on previous research results.

\subsection{Field Investigation Methodology}

The research team made various investigations and survey into Yuanyang Hani Terrace's resources, environment, and development of tourism marketing and community for many times in 2013. Through a large number of field investigations, the study widely collects information, files and data to lay a foundation for researches. 


\subsection{Investigation and Interview}

In order to know the social and economic development of Hani Terrace, as well as visitors' perception and attitude of Hani Terrace tourism, the study applies field observation, semi-structured interview, in-depth interviews of key figures, questionnaire survey and other methods, the study gets firsthand information about the population, employment and income of community families, and the visitors' perception and expectations of tourism, etc.

\section{Analysis on the Results of Investigation into Tourism Market's Characteristics}

Based on the field investigation into the travel area of Hani terrace in Yuanyang from April to October 2013 the paper analyzes the terrace tourism market's characteristics in Yuanyang. The investigation was divided into three groups. They respectively carried out filed investigation into Bus Station, tourist shopping Store, Snack Store, Square and each scenic spot of Yuanyang terrace in Yuanyang. The investigation targeted at the tourists in Yuanyang. In total, 500 questionnaires were delivered. 455 questionnaires were collected. The validity rate reached $91.0 \%$. After summarizing the questionnaires, Table 1 was formed.

Table 1. Results of investigation into Hani terrace tourism market's characteristics in Yuanyang

\begin{tabular}{|c|c|}
\hline $\begin{array}{l}\text { Characteristics } \\
\text { indicator }\end{array}$ & Details \\
\hline Gender & Mainly male tourists; ratio of men to women was about 1.6:1. \\
\hline Age & Mainly from 16 to 55 years old; mainly students, youth and adults. \\
\hline Monthly income & Mainly $1,000-2,999$ Yuan. \\
\hline Education & Tourists with junior college and higher academic degree accounted for $83.78 \%$. \\
\hline $\begin{array}{l}\text { Tourist source } \\
\text { market }\end{array}$ & $\begin{array}{l}\text { Mainly domestic tourists; beyond the province, the tourists mainly come from Guangdong, Shanghai, Zhejiang, Jiangsu, } \\
\text { Beijing, Anhui, Hubei, Jilin, Henan and other provinces. Tourists from Guangdong and Zhejiang account for the majority. In } \\
\text { terms of foreign tourists, they mainly come from Japan, Korea, France, the UK, Netherland, Australia and other countries. } \\
\text { Tourists from Japan and France account for the majority. }\end{array}$ \\
\hline $\begin{array}{l}\text { Transportation } \\
\text { method }\end{array}$ & Long-distance coach (41\%) and self-driving travel; charted traveling bus and other methods only account for $23 \%$. \\
\hline $\begin{array}{l}\text { Method of tourist } \\
\text { companionship }\end{array}$ & $\begin{array}{l}\text { Traveling with friends/colleagues accounts for } 60.36 \% \text {; traveling with family members/lovers accounts for } 28.83 \% \text {; traveling } \\
\text { alone accounts for } 10.81 \% \text {. }\end{array}$ \\
\hline Travelling method & Self-service travel accounts for $63.96 \%$; and travel agency's organization accounts for no more than $10 \%$. \\
\hline $\begin{array}{l}\text { Tourists' } \\
\text { accommodation }\end{array}$ & Common hotels account for about $45.95 \%$; rural hotels account for $27.03 \%$; starred hotels and others account for a small part. \\
\hline $\begin{array}{l}\text { Tourists' tour } \\
\text { itinerary }\end{array}$ & Mainly within two days, accounting for $68.74 \%$; more than three days, accounting for $31.54 \%$. \\
\hline $\begin{array}{l}\text { General } \\
\text { consumption }\end{array}$ & Not high. No more than 1,000 Yuan accounts for the absolute part; lower in scenic spots. \\
\hline $\begin{array}{l}\text { Most popular scenic } \\
\text { spot }\end{array}$ & Jingkou Minsu Village, Bada, Duoyishu, Laohuzui \\
\hline $\begin{array}{l}\text { Approach of } \\
\text { information } \\
\text { perception }\end{array}$ & $\begin{array}{l}\text { Mainly through tourism books and friends' recommendation; a few tourists get the travel information about Yuanyang from } \\
\text { travel agencies, travel promotion, television broadcasting }\end{array}$ \\
\hline Hindering factors & Mainly transportation and time, subtle effects of travel fees, security and so on. \\
\hline Satisfaction degree & Basically satisfied, very unsatisfied and unsatisfied account for a small part; generally satisfied accounts for a large part. \\
\hline
\end{tabular}

Since the 1980s, Hani terrace in Yuanyang has enjoyed an increasingly sound reputation. From the characteristic indicators in Table 1, we can know that: Hani terrace in Yuanyang not only needs to improve its ability of satisfying tourists' demands, but also needs to focus on tourism marketing.

\section{Construction of Marketing System of Yuanyang Terrace}

\subsection{Marketing Objective}

The general marketing objective of Yuanyang terrace is: developing Yuanyang terrace with novel marketing ideas; realizing overall development of Yuanyang terrace with scientific planning; cultivating domestic and foreign tourist sources with advanced marketing technology; promoting the healthy development of the scenic spot with the leverage of the reasonable price; forging the new brand image of Yuanyang terrace with the approach of brand upgrading. 


\subsection{Marketing Organization}

In order to realize the marketing objective of Yuanyang terrace, the modern marketing method should be made full use of. Besides, the comprehensive, multi-layered and multi-faceted scenic spot marketing should be carried out by means of perfecting the system of tourism products, establishing the network of network channel, enhancing the publicity of advertising media, carrying out public promotion, holding activities on festivals, establishing promotion fund and making full use of the Internet for the purpose of promoting Yuanyang terrace's reputation and fame. Therefore, the specific "marketing organization" should be established in the company as soon as possible. The marketing organization should be mainly responsible: (1) Collecting various kinds of market information and provide firsthand information for making a scientific and reasonable marketing plan. (20 Making various marketing plans and activity planning; (3) Making various publicity brochures, albums, CDs, television promotion videos, etc.; carry out overall tourism promotion work; (4) Organizing various tourism trading fairs, expositions and exhibitions; (5) Making, operating and maintaining Yuanyang terrace portal website; (6) Planning and organizing various theme activities.

\subsection{Establish Yuanyang Terrace's Tourism Image Identification System}

VI system (visual identification system): highlight Yuanyang terrace landscape, Hani culture, earthly relaxation resort, tourism themes of several thousands' rice-cultivating culture, especially the combination of Hani culture elements and terrace landscape; select Yuanyang terrace's LOGO, publicity posters, exhibition boards, $\mathrm{VCD} / \mathrm{DVD}$, publicity albums and so on that specific personnel have designed

MI system (mind identification system: the idea that tourists are friends, service is work, and development is what matters; in terms of publicity, publicize to tourists that Yuanyang terrace is the high-end tourism destination that integrates holiday resort, Hani culture folklore tourism, fallow and sightseeing tourism.

BI system (behavior identification system): It requires that Yuanyang terrace Jingkou, Duoyishu, Bada, Laohuzui and other main villages should keep their original features to a certain degree. Tourism practitioner's reception behaviors should possess Hani culture's unique features and conform to national standards for the purpose of proving considerate and perfect services for tourists as much as possible.

\subsection{Marketing Strategies}

Based on the overall marketing, according to features of Yuanyang terrace's resources, advantages and disadvantages, combining with marketing's 4Ps theory, the paper proposes the following marketing strategies:

\subsubsection{Product Strategy}

Because the majority of projects in the scenic spot are pertinent to peak seasons (winter and spring), more projects suitable for slack seasons (summer and autumn) should be designed for the actual situation of the scenic spots, such as Hani Terrace Heat-Relief Tourism Festival, Hani Terrace Autumn Rice-Scent Culture Festival, World Terrace Forum and other festival tourism. Besides, high-end resort tourism and travel experience should be developed. Summer and autumn tourism market should be activated.

\subsubsection{Price Strategy}

(1) Consider reducing the ticket price and even exempt the ticket in slack seasons. Hotels' price should also be greatly discounted off. (2) In slack seasons, singing and dancing activities, Changjie Banquet and other participatory projects should be unfolded for free to attract more people; (3) Give travel agencies more profit return in slack seasons. Based on the bonus marketing plan in relevant travel destinations, Yuanyang terrace can implement "accumulated sales" grouping ticket return plan in travel agencies; reward the groups with a certain scale to different degrees; stimulate the travel agency's passion of publicizing Yuanyang terrace.

\subsubsection{Channel Strategy}

The current refined market of tourist source in Hani terrace in Yuanyang mainly focuses on general sightseeing tourists and art creation tourists. In the future, pertinent point-to-point marketing should be unfolded for specific group combining with the product design: (1) For elites, database marketing should be carried out. Besides, provide distinctive customization services for high-end groups. (2) For large and medium-sized enterprises, contact Union of Labor actively, encourage and organize employees to carry out outdoor expansion training, hiking or sports outdoor. Besides, provide discounts to different degrees according to the number of tourists. (3) For self-driving tourists, provide itinerary guidance, e-map and other services for self-driving tourists through contacting self-driving clubs. (4) For outdoor activity lovers, provide the information related to scenic spots through phone calls or short message regularly and carry out camping activities in scenic spots in the form of clubs; (5) For art creators, besides delivering latest scenery pictures to them, create a sound online trading 
platform and art agent system to provide favorable art creation and trading environment.

\subsubsection{Promotion Strategy}

(1) Event promotion: Expand the scope of effects by making use of Hani terrace's heritage application event; carry out Hani terrace's tourism image marketing by seizing the opportunity of 2010 Shanghai World Expo.

(2) Culture promotion: Invite famous directors to make videos themed on Hani terrace; promote the popularity through creating terrace photography and painting basement; rehearse "Terrace Impression" singing \& dancing; emulate "Yunnan Impression" to carry out touring performances; publicize terrace's image.

(3) Experience promotion: Invite artists and actors to visit Hani terrace and form the most important reputation on the market;

(4) Sponsorship promotion: "Yuanyang Terrace" Airship tours round the whole province and nation; after Kunming-Hekou Railway is established and open to traffic, sponsor "Yuanyang Terrace" train;

(5) Joint promotion: Combine with tourism projects with competitiveness in Honghezhou to carry out marketing, such as cultural tourism in Jianshui, Yunnan-Vietnam Railway, etc. The combination advantage can be formed. Besides, Guangxi Longsheng Longji Terrace, Hunan Xinhua Ziquejie terrace can be combined to apply for world natural and cultural heritage so as to forge the regional tourism image of "China's Southern Terrace"; Carry out "Global Curve Art" international marketing by combining the Great Wall and other China's world cultural heritage; establish world terrace forum with famous terrace sites to forge "World Terrace Heritage" Brand; cooperate with Sabah in Vietnam to enjoy European tourist market focusing on France.

(6) Take part in the tourism fair: At present, various forms of tourism fairs in China are a very good approach for scenic spot to promote themselves. Yuanyang terrace should actively take part in specific publicity organized by Provincial Tourism Bureau every year. At the same time, it should work with Shangri-la, Tengchong and other non-direct competitive scenic spots to establish the marketing team to carry out joint publicity in first-tier tourist source market so as to spread the influence and expand fame and reputation.

(7) Public promotion: Directly communicate with large state-owned enterprises in Yunnan Province, undertake large commercial and governmental conferences, contact team tourists; cooperate with Honghe Tourism Bureau to propose tourism publicity support to Yunnan Provincial Tourism Bureau and give support in terms of the construction of public affairs, governmental tourism publicity fund, publicity channels, relevant policies, fund attraction and so on.

(8) One-to-one promotion: Set up Yuanyang Terrace Tourism Affair-handling Office in Kunming, Honghe, Guangzhou, Shanghai, Beijing, Japan, Korea, France and other first-tier tourist source sites; be responsible for the promotion of major travel agencies with tourist sources and provide greatest discount for the participant travel agencies; allocate cash profits at the end of the year.

(9) Festival event promotion: Attract more tourists through holding various travel activities, keep regular tourists. The details of festival activities are shown as follows: (1) Yuanyang terrace international photography week: In November every year to March next year, choose one to two weeks and invite domestically and internationally important photography associations to take part in photography competitions in Yuanyang terrace. Set the prize with a large amount of rewarding. Entrust a specific organization to undertake the responsibilities; (2) Hani Terrace Culture - International Forum Week: In the first week in January every year, invite domestic and foreign famous cultural experts to take part to explore into Hani terrace's culture. Set up relevant research fund supporting projects and improve Hani terrace's influence in the cultural field. (3) Hani terrace sightseeing festival: In December every year, it can be carried with Yuanyang terrace international photography week synchronously. "Live in mushroom house, eat Hani minority's food, appreciate Hani terrace's scenery, feel Hani terrace's frog, and catch Yuanyang terrace's fish. (4) Hani terrace's food festival: It is held in January in the lunar calendar every year, i.e., it is held together with Hani minority's "Mao Ma Tu". Changlong Banquet is prepared so that tourists can enjoy Hani's delicacies. (5) Hani Autumn appreciation festival: It is held around May First every year, together with May First golden week. A grand autumn appreciation activity is held. Tourists are invited to taste the local snacks, such as glutinous buns, etc. (6) Hani terrace relaxation festival: It is held between June 15 and August 30 every year.

\subsection{Marketing Control}

The market is dynamic and changing. Tourism marketing may be inconsistent with the pre-set objectives. A relatively feasible method is to set up marketing research team. Outdoor researchers can carry out investigations at different time and places. Such an interview should be conducted once every three months so as to evaluate 
the effects of promotion. At the end of the promotion year, annual plan control, profitability ratio control, efficiency control, strategic control and other analysis and evaluation on marketing control approaches should be launched. Besides, marketing activities should be examined based on the information and materials to plan the marketing schemes next year.

\section{Conclusions}

Through exploring into the marketing strategy in Yuanyang terrace tourism market, the paper proposes general marketing strategies and specific marketing objectives. Besides, the paper designs the overall marketing strategy and planning as well as specific marketing strategy and plan. The implementation of the marketing strategy is a huge project, which requires close cooperation in several aspects. Noticeably, some thoughts still need detection and revision in practices for the purpose of avoiding from deficiencies and spreading the merits. The specific marketing organization should be established. It is also urgent to set up Yuanyang terrace tourism image identification system. Only through this can Hani terrace in Yuanyang realize its overall marketing objective as well as long-term development. In addition, culture is a key element in the brand construction. The new brand image pays more attention to the culture, which his remarkably featured with intensive permeability. On the one hand, the original culture penetrates through every aspect of life. It requires consideration on which form should be adopted to demonstrate it in front of tourists. On the other hand, it requires more considerate planning how to maintain and protect the original culture so that it can avoid from foreign culture's shocks. With the gradual proceeding of Yuanyang terrace travel area's marketing work, the unique and grand terrace landscape in the scenic spot as well as primitive and simple Hani culture brings a broader development prospect for Yuanyang terrace's tourism industry.

\section{References}

Hu, W. Y., \& Dong, M. (2008). Spatio-temporal Changes of land use in Yuanyang Country. Yunnan geographic environment research, 20(5), 18-23.

Huang, S. W. (2004). On Developing Ecological Tourism of the Terraced field Culture in Yuanyang. Journal of Honghe University, 2(1), 69-74.

Jiao, Y. M., Xiao, D. N., \& Cheng, G. D. (2002). Study on the Coordinating Development of Ethnic Culture and Natural Environment in Subtropic Mountain Areas-A Case of Cultural Landscape of Hani Terrace in Yuanyang County. Journal of Mountain Science, 20(3), 266-271.

Liu, D. P. (2008). Study on Employees Engaged Earlier in Rural Community Tourism Industry: Enlightenment from the Case of Yuanyang Hani Terrace. Tourism Tribune, 23(8), 45-51.

Lu, S. Z. (2006). Nature Reserve Construction and the Tourism Development of Hani Terrace-A case of Guanyingshan Nature Reserve, Yuanyang, Yunnan. Ecological Economy, (05), 207-211.

Luo, J. L. (2003). Elementary Introduction to Prospect and Development of Tourism of Terraced Fields in Yuanyang. Journal of Mengzi Teachers College, 5(1), 66-69.

Rao, B. Y., Wang, J., Yang, J. R., \& Han, Y. (2009). Evaluation Study on the Eco-environmental Water Demand in Yuanyang Terrace Irrigated Area Based on the Analytic Hierarchy Process. Journal of Water Resources \& Water Engineering, 20(1), 35-39.

Zhang, W. D., \& Lu, C. G. (2003).The Conception of the Developing of Minority Cultural Village at Yuanyang Core Area of Hani Terrace. Journal of Mengzi T teacher's College, 5(1), 62-65.

Zhu, Y. Y. (2009). Remarks on the Application for World Cultural Heritage of the Hani Paddy- Rice Terraces. Academic Exploration, (03), 14-15.

\section{Copyrights}

Copyright for this article is retained by the author(s), with first publication rights granted to the journal.

This is an open-access article distributed under the terms and conditions of the Creative Commons Attribution license (http://creativecommons.org/licenses/by/ 